\title{
Mathematical Modelling of the Volumetric Efficiency for Fluted Rolls Metering Different Crop Seeds ${ }^{\#}$
}

\author{
Muhammed Hakan Özdemir1,a, Adnan Değirmencioğlu ${ }^{1, b, *}$, \\ ${ }^{1}$ Department of Agricultural Machinery and Technologies Engineering, Faculty of Agriculture, Ege University, 35100 Izmir, Turkey \\ *Corresponding author
}

\begin{tabular}{|c|c|}
\hline A R T I C L E I N F O & A B S T R A C T \\
\hline $\begin{array}{l}{ }^{\#} \text { This paper was extracted from the } \\
\text { MSc Thesis of the first author. } \\
\text { Research Article } \\
\text { Received : } 22 / 07 / 2020 \\
\text { Accepted : 07/09/2020 } \\
\text { Keywords: } \\
\text { Planting by seed drills } \\
\text { Seed flow } \\
\text { Flow evenness } \\
\text { Empirical models } \\
\text { Model selection }\end{array}$ & $\begin{array}{l}\text { The objective of this study was to develop a mathematical model for predicting the volumetric } \\
\text { efficiency for fluted rolls metering different crop seeds. A special test stand was designed and } \\
\text { manufactured in order to conduct experiments in order to find out the volumetric efficiency of the } \\
\text { fluted rolls. In order to meet the above objective, alfalfa, barley, coriander, flax, oat, rye, safflower, } \\
\text { sesame and wheat seeds were used. Experiments were conducted at different roll revolutions and } \\
\text { roll lengths by considering the seed rate for each crop and the rolls were driven by a step motor as } \\
\text { controlled by a software installed on a laptop computer. Five replications were achieved for each } \\
\text { experiment and a total of } 1660 \text { flow rate data was obtained. Five different models for volumetric } \\
\text { efficiency were developed. Analysis based on different goodness of fit criteria were achieved to } \\
\text { compare models in to order to select the appropriate one. The study conducted not only resulted in } \\
\text { developing volumetric efficiency models but also revealed an important finding based on low flow } \\
\text { evenness (low } \mathrm{CV}, \% \text { ) values obtained as compared to other studies in the literature. }\end{array}$ \\
\hline
\end{tabular}

\section{Introduction}

For about a century, drilling has been the dominant technique for seed placement into the soil. The metering devices used on drills are usually fluted or studded rollers and also multi-flight augers generally used for metering granular fertilizers were also adopted for metering seeds such as grains and some other crops such as alfalfa seeds that are small in terms of size and have low bulk density. The amount of material flow rate and flow evenness from a fluted roller could be considered as a simple phenomenon but the problem actually is complex once many factors contributing to this physical system are considered. In such a system; constructional, operational parameters and the properties of the material being conveyed determine the flow rate and flow uniformity. The constructional parameters are flute diameter, flute shape, flute volume, the number of flutes, flute helix angle, active flute length and bottom flap space (Ryu and Kim, 1998; Turgut et al., 1996; Güler, 2005; Onal, 2006; Onal and Ertuğrul, 2011a, Onal and Ertuğrul, 2011b). The operational related parameter is the rotational speed of the fluted roller. On the other hand, the physical properties of the material conveyed also affect the flow. Under the same constructional and operational conditions, the flow rate and evenness vary from one material to another. The main properties of a material in this study were considered to be the bulk density, the shape and the size of the material and the friction coefficients of material on material and material on roller surface.
Yıldırım et al. (2004), determined that semi-circular shaped flutes have better flow rate uniformity of wheat and barley seeds than trapezoidal shaped flutes. Bottom flow roller provides lowest coefficient of variation (CV) as $2.92 \%$ for wheat and $3.93 \%$ for barley.

Y1ldırım and Turgut (2007), determined best flow regularity of small seeds like alfalfa and sesame seeds at semi-circular shaped flutes instead of trapezoidal and triangular shaped flutes. The best results were observed at 5-10 rpm and $8 \mathrm{~mm}$ active length of fluted roller which has $56 \mathrm{~mm}$ diameter and 22 semi-circular shaped flutes. In these circumstances, CV values that shows seed flow regularity are mentioned as between $7 \%-13 \%$ for alfalfa seeds and $10 \%-21 \%$ for sesame seeds. Zender ve Önal (1987) studied on seeding legumes and used different seeding units. One of the seeding unit was the one equipped with fluted rolls. The study revealed that the seed rate varied once the forward speed (rpm of the roll) changed. This seeding unit was only appropriate for seeding lentil seeds but the seeding performance was not satisfactory.

As understood from the literature review, the studies conducted using different crop seeds were to find out the performance of the fluted rolls but there exists no mathematical model to predict the volumetric efficiency and/or flow rate. Hence, a study was conducted and the objective of this study was to develop mathematical models and to select one in order to predict the volumetric efficiency and flow rate for different crop seeds as they are delivered by fluted rolls. 


\section{Materials and Method}

In order to develop volumetric efficiency model for the fluted rolls, the crop seeds planted by seed drills such as alfalfa, barley, coriander, flax, oat, rye, safflower, sesame and wheat were used in this study. The physical properties of the seeds are tabulated in Table 1.

To measure the flow rate in this study, a special test stand was designed and manufactured. The test stand is depicted in Figure 1.

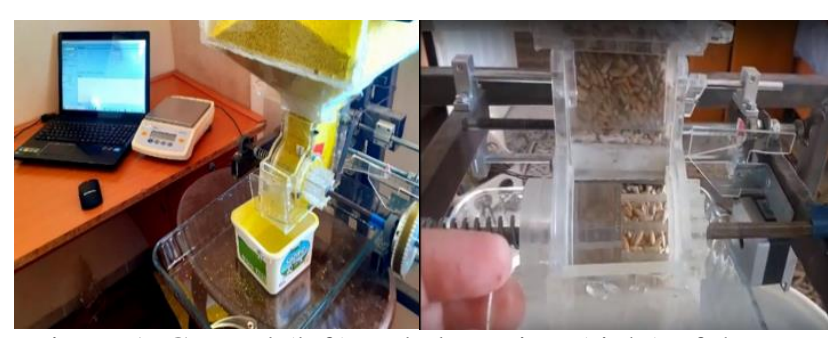

Figure 1. General (left) and close view (right) of the test unit equipped with fluted rolls as manufactured to determine the volumetric efficiency

In this test stand, the roll length can be adjusted at different values and it was designed to use with rolls in the diameter of 25 and $50 \mathrm{~mm}$. The roll was driven by a step motor $(0.55 \mathrm{Nm})$ and control system consisted of an Arduino Uno R3, Arduino CNC Shield, DC power source (19V, 4.74A), data cable. The step motor was controlled by Universal Gcode Sender software and the rotational speed of the roll can be changed between 0 and 500 rpm with an accuracy of \pm 0.1 . The flow rates for different crops seeds at different rpm and roll length were obtained for one minute and each experiment was replicated five times. The experiment design is tabulated in Table 2.

Before carrying out the experiments, some theoretical flow rate calculations were made in order to compare with the experimental flow rate so that the volumetric efficiency can be readily obtained. The calculations on the other hand indicated that the use of roll at a diameter of $25 \mathrm{~mm}$ is not appropriate for barley, oat, rye, safflower and wheat. As a result of these calculations, a total of 1660 flow rate data were obtained. The theoretical volumetric efficiency was calculated as in the following.

Table 1. Physical properties of the seeds used in the study

\begin{tabular}{|c|c|c|c|c|c|c|c|c|c|}
\hline Seeds & $\mathrm{m}_{1000^{* * *}}$ & $\gamma^{* *}$ & $\overline{\mu_{1^{* * *}}}$ & $\mu_{2^{* * *}}$ & Moisture** & $1^{*}$ & $\mathrm{~W}^{*}$ & $\mathrm{t}^{*}$ & $\phi$ \\
\hline seeas & $\mathrm{g}$ & $\mathrm{kg} / \mathrm{m}^{3}$ & - & - & $\%$; wb*** & $\mathrm{mm}$ & $\mathrm{mm}$ & $\mathrm{mm}$ & - \\
\hline Alfalfa & $\begin{array}{l}3.3 \\
(0)\end{array}$ & $\begin{array}{c}834.79 \\
(1.13)\end{array}$ & $\begin{array}{c}0.569 \\
(0.018)\end{array}$ & $\begin{array}{c}0.368 \\
(0.005)\end{array}$ & $\begin{array}{c}5.79 \\
\left(3.2 \times 10^{-14}\right)\end{array}$ & $\begin{array}{c}2.38 \\
(0.184)\end{array}$ & $\begin{array}{c}1.52 \\
(0.127)\end{array}$ & $\begin{array}{c}1.18 \\
(0.107)\end{array}$ & 0.68 \\
\hline Barley & $\begin{array}{c}41.02 \\
(0.061)\end{array}$ & $\begin{array}{l}657.29 \\
(0.364)\end{array}$ & $\begin{array}{c}0.521 \\
(0.009)\end{array}$ & $\begin{array}{l}0.323 \\
(0.02)\end{array}$ & $\begin{array}{l}11.08 \\
(0.06)\end{array}$ & $\begin{array}{c}9.16 \\
(0.72)\end{array}$ & $\begin{array}{c}3.53 \\
(0.24)\end{array}$ & $\begin{array}{c}2.61 \\
(0.23)\end{array}$ & 0.48 \\
\hline Coriander & $\begin{array}{c}6.2 \\
(0.029)\end{array}$ & $\begin{array}{l}340.44 \\
(0.271)\end{array}$ & $\begin{array}{c}0.494 \\
(0.012)\end{array}$ & $\begin{array}{c}0.339 \\
(0.013)\end{array}$ & $\begin{array}{l}7.06 \\
(0.4)\end{array}$ & $\begin{array}{c}3.61 \\
(0.310)\end{array}$ & $\begin{array}{c}2.85 \\
(0.254)\end{array}$ & $\begin{array}{c}2.66 \\
(0.243)\end{array}$ & 0.83 \\
\hline Flax & $\begin{array}{c}6.54 \\
(0.015)\end{array}$ & $\begin{array}{l}685.12 \\
(0.477)\end{array}$ & $\begin{array}{c}0.404 \\
(0.01)\end{array}$ & $\begin{array}{c}0.29 \\
(0.011)\end{array}$ & $\begin{array}{c}7.04 \\
(0.12)\end{array}$ & $\begin{array}{c}4.84 \\
(0.268)\end{array}$ & $\begin{array}{c}2.5 \\
(0.142)\end{array}$ & $\begin{array}{c}1.02 \\
(0.107)\end{array}$ & 0.48 \\
\hline Oat & $\begin{array}{c}30.9 \\
(0.039)\end{array}$ & $\begin{array}{l}554.31 \\
(0.183)\end{array}$ & $\begin{array}{l}0.515 \\
(0.02)\end{array}$ & $\begin{array}{l}0.343 \\
(0.06)\end{array}$ & $\begin{array}{l}11.37 \\
(0.06)\end{array}$ & $\begin{array}{c}10.35 \\
(0.895)\end{array}$ & $\begin{array}{c}2.82 \\
(0.230)\end{array}$ & $\begin{array}{c}2.23 \\
(0.212)\end{array}$ & 0.39 \\
\hline Rye & $\begin{array}{l}28.56 \\
0.073\end{array}$ & $\begin{array}{l}759.25 \\
(0.582)\end{array}$ & $\begin{array}{c}0.419 \\
(0.011)\end{array}$ & $\begin{array}{l}0.323 \\
(0.02)\end{array}$ & $\begin{array}{c}12.1 \\
(0.05)\end{array}$ & $\begin{array}{c}7.65 \\
(0.788)\end{array}$ & $\begin{array}{c}2.6 \\
(0.557)\end{array}$ & $\begin{array}{c}2.53 \\
(0.206)\end{array}$ & 0.48 \\
\hline Safflower & $\begin{array}{c}39.8 \\
(0.095)\end{array}$ & $\begin{array}{l}509.67 \\
(0.302)\end{array}$ & $\begin{array}{c}0.501 \\
(0.011)\end{array}$ & $\begin{array}{l}0.361 \\
(0.02)\end{array}$ & $\begin{array}{l}6.65 \\
(0.2)\end{array}$ & $\begin{array}{c}7.75 \\
(0.499)\end{array}$ & $\begin{array}{c}4.28 \\
(0.333)\end{array}$ & $\begin{array}{c}3.55 \\
(0.255)\end{array}$ & 0.63 \\
\hline Sesame & $\begin{array}{c}2.42 \\
(0.004)\end{array}$ & $\begin{array}{l}656.75 \\
(0.125)\end{array}$ & $\begin{array}{c}0.363 \\
(0.008)\end{array}$ & $\begin{array}{c}0.23 \\
(0.001)\end{array}$ & $\begin{array}{c}3.41 \\
(0.16)\end{array}$ & $\begin{array}{c}3.03 \\
(0.291)\end{array}$ & $\begin{array}{c}1.75 \\
(0.146)\end{array}$ & $\begin{array}{c}0.73 \\
(0.081)\end{array}$ & 0.52 \\
\hline Wheat & $\begin{array}{c}40.38 \\
(0.119)\end{array}$ & $\begin{array}{l}746.51 \\
(0.073)\end{array}$ & $\begin{array}{l}0.519 \\
(0.02)\end{array}$ & $\begin{array}{c}0.33 \\
(0.002)\end{array}$ & $\begin{array}{l}13.39 \\
(0.03)\end{array}$ & $\begin{array}{c}7.68 \\
(0.443)\end{array}$ & $\begin{array}{c}3.07 \\
(0.290)\end{array}$ & $\begin{array}{c}2.86 \\
(0.256)\end{array}$ & 0.53 \\
\hline
\end{tabular}

*: mean of 100 samples; ** mean of three replications; ***: wet base; the numbers in paranthesis are the standard deviations; $\phi=\frac{\sqrt[3]{l . w . t}}{l}($ Mohsenin, 1986$)$
The relationship between volumetric and mass flow rate can be written as.

$$
\mathrm{V}_{\mathrm{Qvteo}}=\mathrm{Q}_{\mathrm{mteo}} / \gamma=\mathrm{A} . \mathrm{L} . \mathrm{n}=\mathrm{V} \mathrm{n}
$$

Where;

$\mathrm{V}_{\text {Qvteo }}$ : Theoretical volumetric flow rate $\left(\mathrm{mm}^{3} \mathrm{~min}^{-1}\right)$

$\mathrm{Q}_{\mathrm{mteo}}$ : Theoretical mass flow rate $\left(\mathrm{g} \mathrm{min}^{-1}\right)$

$\gamma \quad$ : Bulk density of the material being conveyed $\left(\mathrm{g} \mathrm{mm}^{-3}\right)$

A : Total area of the roll $\left(\mathrm{mm}^{2}\right)$

$\mathrm{L}$ : Active length of the roll (mm)

$\mathrm{n} \quad$ : Speed of the roll (rpm)

$\mathrm{V} \quad$ : Total volume of the roll $\left(\mathrm{mm}^{3}\right)$

$$
\mathrm{Q}_{\text {mexp }} / \mathrm{Q}_{\mathrm{mteo}}=\eta
$$

Where;

$$
\mathrm{Q}_{\text {mexp }}=\text { Experimental (measured) flow rate }\left(\mathrm{g} \mathrm{min}^{-1}\right)
$$

The data obtained from the experiments were analyzed by using Microsoft Excel and Minitab V19.

The flow uniformity as calculated from five replications was evaluated and discussed based on the reference values as tabulated in Table 3.

The theoretical form of the mathematical model for the volumetric efficiency can be written as in the following form:

$$
\eta=f\left(\mathrm{~V}, \mathrm{n}, \mathrm{m}_{1000}, \gamma, \mu_{1}, \mu_{2}, \mathrm{l}, \mathrm{w}, \mathrm{t}\right)
$$

Where;
$\eta \quad:$ : Volumetric efficiency (-)
$\mathrm{V} \quad$ : Total volume of the fluted roll $\left(\mathrm{mm}^{3}\right)$
n : Roll speed (rpm)
$\mathrm{m}_{1000} \quad$ :Thousand seed mass $(\mathrm{g})$
$\gamma \quad:$ Bulk density $\left(\mathrm{kg} \mathrm{m}^{-3}\right)$
$\mu_{1} \quad$ :Friction coefficient of material on material (-)
$\mu_{2} \quad$ : Friction coefficient of material on plexiglas (-)
$1, \mathrm{w}$ and $\mathrm{t}$ : Length, width and thickness of the seed (mm) 
Table 2. Experimental design for the determination of flow rate and volumetric efficiency

\begin{tabular}{|c|c|c|c|c|}
\hline Material & Roll & Roll length (L-mm) & Roll speed (n-rpm) & Total number of experiments (L.n) * \\
\hline \multirow{2}{*}{ Alfalfa } & $\mathrm{M}_{1}$ & $6,8,10$ & $3,4,5,6,8,15,20$ & 21 \\
\hline & $\mathrm{M}_{2}$ & 6,8 & $3,4,5,8,20$ & 10 \\
\hline Barley & $\mathrm{M}_{2}$ & $9,12,15,20,25,30$ & $9,11,14,17,20,30,40$ & 42 \\
\hline \multirow{2}{*}{ Coriander } & $\mathrm{M}_{1}$ & $6,8,10$ & $9,11,14,17,20,40$ & 18 \\
\hline & $\mathrm{M}_{2}$ & $6,8,10,12$ & $5,7,9,15$ & 16 \\
\hline \multirow{2}{*}{ Flax } & $\mathrm{M}_{1}$ & $10,13,15$ & $30,35,41,44,60$ & 15 \\
\hline & $\mathrm{M}_{2}$ & $9,12,15,20,25,30$ & $9,11,14,17,20,30,40$ & 42 \\
\hline Oat & $\mathrm{M}_{2}$ & $15,20,25,30$ & $9,11,14,17,20,30,40$ & 28 \\
\hline Rye & $\mathrm{M}_{2}$ & $9,12,15,20,25,30$ & $9,11,14,17,20,30,40$ & 42 \\
\hline Safflower & $\mathrm{M}_{2}$ & $8,10,15,20$ & $5,8,14,20,25,30,35$ & 28 \\
\hline \multirow{2}{*}{ Sesame } & $\mathrm{M}_{1}$ & $6,8,10,12,15$ & $6,11,18,30,40$ & 25 \\
\hline & $\mathrm{M}_{2}$ & 6,8 & $6,11,18,30,40$ & 10 \\
\hline Wheat & $\mathrm{M}_{2}$ & $9,15,20,25,30$ & $9,11,14,17,20,30,40$ & 35 \\
\hline Total & & & & 332 \\
\hline
\end{tabular}

$\mathrm{M}_{1}:$ roll $\varnothing 25 \mathrm{~mm} ; \mathrm{M}_{2}$ : roll $\varnothing 50 \mathrm{~mm}$; *: without replications

Table 3. Evaluation of CV (\%) values as calculated from replications (Önal, 2006)

\begin{tabular}{c|c}
\hline CV $(\%)$ & Evaluation \\
\hline$<1$ & Excellent \\
$1-2$ & Good \\
$2-3$ & Sufficient \\
$3-4$ & Acceptable \\
$>4$ & Insufficient \\
\hline
\end{tabular}

Table 4. Theoretical volumetric efficiency model forms considered in the study

\begin{tabular}{|c|c|c|c|}
\hline Model no & Model description & Theoretical form of the model & \\
\hline I & Linear model & 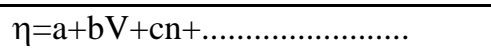 & $\mathrm{kt}$ \\
\hline II & Volumetric efficiency transformed linear model & $\operatorname{Arcsin} \sqrt{n}=a+b V+c n+\ldots \ldots \ldots$ & $\mathrm{kt}$ \\
\hline III & Volumetric efficiency transformed linear model & $\log \left(\frac{n}{1-n}\right)=\mathrm{a}+\mathrm{bV}+\mathrm{cn}+\ldots \ldots \ldots \ldots$ & $\mathrm{kt}$ \\
\hline IV & Power model & 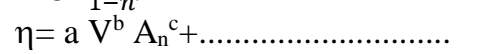 & $\mathrm{t}^{\mathrm{k}}$ \\
\hline $\mathrm{V}$ & Volumetric efficiency transformed power model & $\log \left(\frac{n}{1-n}\right)=\mathrm{a} \mathrm{V} \mathrm{V}^{\mathrm{b}} \ldots \ldots \ldots \ldots \ldots \ldots \ldots \ldots \ldots \ldots \ldots \ldots \ldots$ & $\mathrm{t}^{\mathrm{k}}$ \\
\hline
\end{tabular}

Five different mathematical model forms were considered in the study as tabulated in Table 4. The stepwise procedure was applied and the probability level of $95 \%$ was selected to form the models. Some transformations in some models were made such as $\operatorname{Arcsin} \sqrt{\eta}$ and $\log \left(\frac{\eta}{1-\eta}\right)$ in order to avoid volumetric efficiency predictions exceeding unity or $100 \%$.

In order to select the best model among five models developed, some analysis was made and two goodness of fit criteria in addition to correlation coefficient ( $r$ ) were used to compare the models. These two criteria are given as in the following.

$$
\begin{aligned}
& \mathrm{E}_{\mathrm{RMS}}=\left[\frac{1}{\mathrm{~N}} \sum_{\mathrm{i}=1}^{\mathrm{N}}\left(\mathrm{Q}_{\text {pred., }}-\mathrm{Q}_{\text {mea., }}\right)^{2}\right]^{1 / 2} \\
& \chi^{2}=\frac{\sum_{\mathrm{i}=1}^{\mathrm{N}}\left(\mathrm{Q}_{\text {pred., }}-\mathrm{Q}_{\text {mea., }}\right)^{2}}{\mathrm{~N}-\mathrm{n}_{1}}
\end{aligned}
$$

Where;

$$
\begin{aligned}
& \mathrm{E}_{\mathrm{RMS}} \text { : Root mean square error } \\
& \chi^{2}: \text { Khi square } \\
& \mathrm{Q}_{\text {pre. }}: \text { Predicted flow rate }\left(\mathrm{g} \mathrm{min}^{-1}\right) \\
& \mathrm{Q}_{\text {mea. }} \text { : Measured flow rate }\left(\mathrm{g} \mathrm{min}^{-1}\right) \\
& \mathrm{N} \quad: \text { Number of measurements } \\
& \mathrm{n} \quad: \text { Number of model constants }
\end{aligned}
$$

The higher the coefficient of correlation ( $r$ ) and the lower the $\mathrm{E}_{\mathrm{RMS}}$ and $\chi^{2}$ are, the better the models predict.

\section{Results}

The flow rate as a function of roll speed (rpm) and roll length as an example for barley is depicted in Figure 2. As seen from the figure, the flow rate increases linearly as the roll speed and roll length increases.

An increase in roll length increases the flow efficiency while increase in roll speed reduces the flow efficiency. These are depicted in Figure 3 and 4 for coriander and wheat seeds.

The coefficient of variation (CV) as an indicator of flow uniformity was calculated from five replications for each crop. One of the examples for CV (\%) evaluations are shown in Figure 5 for rye seeds. As seen from the figure, the increase in roll length and speed causes a reduction in $\mathrm{CV}$ values generally but there are some fluctuations in $\mathrm{CV}$ values. The results obtained from the experiments for $\mathrm{CV}$ (\%) values are tabulated in Table 5 as they are evaluated based on the criteria set by Önal (2011).

As seen from the table, the CV (\%) values obtained from 332 experiments mostly took place within $<1$ and $1<\mathrm{CV}<2$ with 78 and $17.8 \%$, respectively. Considering all replications, the $\mathrm{CV}$ values are in the range of $\mathrm{CV}<4$ with a percentage of 99.7 .

In developing mathematical models, the total volume (V) of the roll was considered instead of considering roll length (L) and total area (A). The models developed are given below along with the coefficient of determination values $\left(R^{2}\right)$. 


\section{Model No: I (Linear model)}

$\eta=0.7993+0.000369 . \mathrm{g}+0.000009 . \mathrm{V}-0.002282 . \mathrm{n}-0.1638 . \mu_{1}-0.3533 . \mu_{2}-0.048571 .1+0.04255 . \mathrm{w}+0.01781 . \mathrm{t}\left(\mathrm{R}^{2}=0.896\right)$

Model No: II (Volumetric efficiency transformed linear model)

$\operatorname{Arcsin} \sqrt{\eta}=1.0984-0.1563 . \mu_{1}-0.3489 . \mu_{2}+0.000010 \mathrm{~V}+0.000404 . \mathrm{g}-0.002671 . \mathrm{n}-0.053621 .1+0.05014 \mathrm{w}+0.00912 . \mathrm{t}\left(\mathrm{R}^{2}=0.893\right)$

Model No: III (Volumetric efficiency transformed linear model)

$\log \left(\frac{\eta}{1-\eta}\right)=0.5803-0.2515 . \mu_{1}-0.626 . \mu_{2}+0.000021 \mathrm{~V}+0.000778 . \mathrm{g}-0.005477 . \mathrm{n}-0.10407 .1+0.10091 . \mathrm{w}\left(\mathrm{R}^{2}=0.886\right)$

Model No: IV (Power model)

$\eta=10^{-1.3793} \cdot \mathbf{V}^{0.09528} \cdot \mathbf{g}^{0.35588} \cdot \mathbf{n}^{-0.04428} \cdot \boldsymbol{\mu 1}^{-0.3243} \cdot \boldsymbol{\mu}^{-0.1399} \cdot \mathbf{l}^{-52749} \cdot \mathbf{w}^{0.29} \cdot \mathbf{t}^{0.115744}\left(\mathrm{R}^{2}=0.889\right)$

Model No: V (Volumetric efficiency transformed power model)

$\frac{\eta}{\mathbf{1 - \eta}}=10^{-3.3054} \cdot \boldsymbol{\mu}_{\mathbf{1}^{-0.8006}} \cdot \boldsymbol{\mu \mathbf { 2 }}^{-0.2557} \cdot \mathbf{V}^{0.36809} \cdot \mathbf{g}^{1.0936} \cdot \mathbf{n}^{-0.18285} \cdot \mathbf{I}^{-1.7072} \cdot \mathbf{w}^{0.9284} \cdot \mathbf{t}^{0.1059}\left(\mathrm{R}^{2}=0.894\right)$

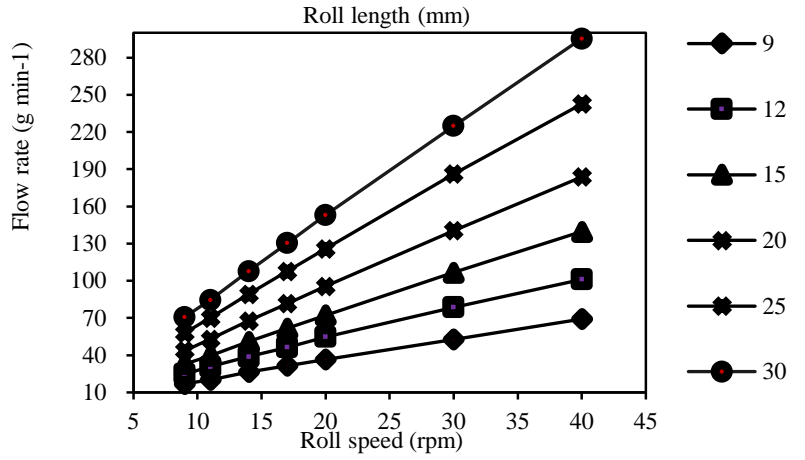

Figure 2. Flow rate for barley as a function of roll speed and roll length (Roll $\varnothing 50 \mathrm{~mm}$ )

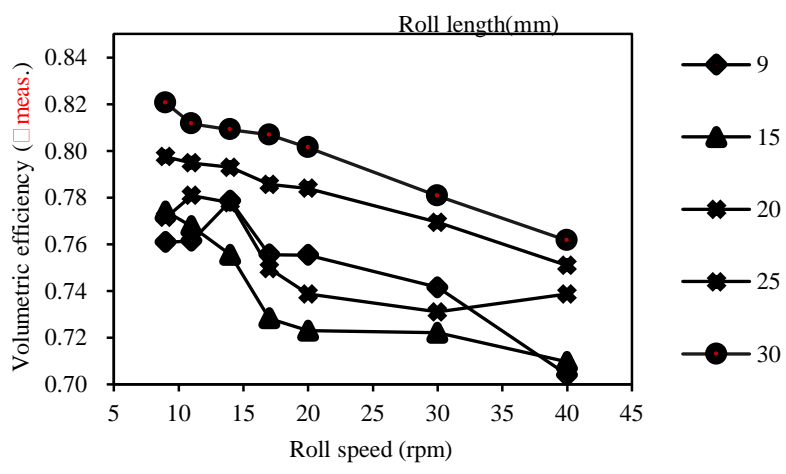

Figure 4. Effects of roll speed on length on volumetric efficiency for wheat seeds (Roll $\varnothing 50 \mathrm{~mm}$ )

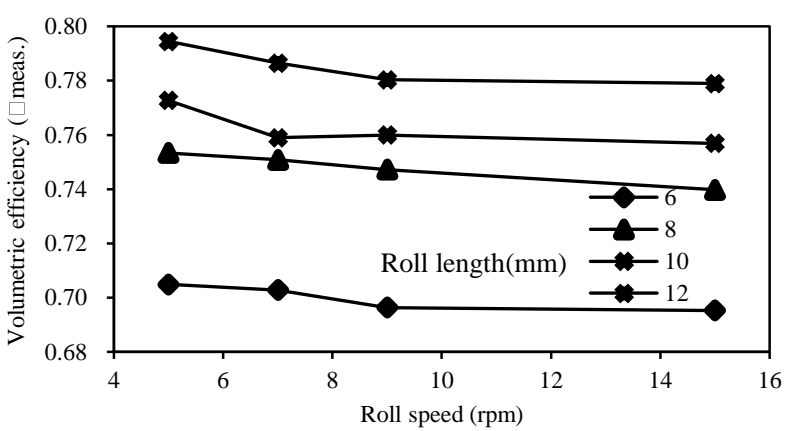

Figure 3. Volumetric efficiency as a function of roll speed and length for coriander (Roll $\varnothing 50 \mathrm{~mm})$

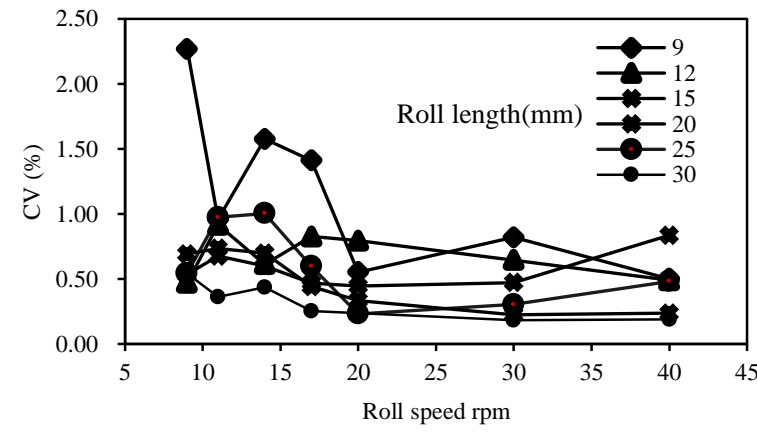

Figure 5. Effects of roll speed and length on flow uniformity $(\mathrm{CV} \%)$ values for rye seeds (Roll $\varnothing 50 \mathrm{~mm})$

Table 5. Distribution of experiments as percentages and number of experiments based on the flow uniformity (CV, \%) range for different crop seeds considered in this study

\begin{tabular}{|c|c|c|c|c|c|c|}
\hline \multirow{2}{*}{ Seeds } & \multirow{2}{*}{ Roller } & \multicolumn{5}{|c|}{$\mathrm{CV}(\%)$} \\
\hline & & $<1$ & $1-2$ & $2-3$ & $3-4$ & $>4$ \\
\hline \multirow{2}{*}{ Alfalfa } & $\mathrm{M}_{1}$ & $90.5 \%$ (19) & $9.5 \%(2)$ & $0(0)$ & $0(0)$ & $0(0)$ \\
\hline & $\mathrm{M}_{2}$ & $100 \%(10)$ & $0(0)$ & $0(0)$ & $0(0)$ & $0(0)$ \\
\hline Barley & $\mathrm{M}_{2}$ & $66.7 \%(28)$ & $23.8 \%(10)$ & $7.1 \%(3)$ & $2.4 \%(1)$ & $0(0)$ \\
\hline \multirow{2}{*}{ Coriander } & $\mathrm{M}_{1}$ & $33.3 \%(6)$ & $61.1 \%(11)$ & $5.6 \%(1)$ & $0(0)$ & $0(0)$ \\
\hline & $\mathrm{M}_{2}$ & $87.5 \%(14)$ & $12.5 \%(2)$ & $0(0)$ & $0(0)$ & $0(0)$ \\
\hline \multirow{2}{*}{ Flax } & $\mathrm{M}_{1}$ & $100 \%(15)$ & $0(0)$ & $0(0)$ & $0(0)$ & $0(0)$ \\
\hline & $\mathrm{M}_{2}$ & $90.5 \%(38)$ & $9.5 \%(4)$ & $0(0)$ & $0(0)$ & $0(0)$ \\
\hline Oat & $\mathrm{M}_{2}$ & $32.1 \%(9)$ & $46.4 \%(13)$ & $10.7 \%(3)$ & $7.1 \%(2)$ & $3.6 \%(1)$ \\
\hline Rye & $\mathrm{M}_{2}$ & $90.5 \%(38)$ & $7.1 \%(3)$ & $2.4 \%(1)$ & $0(0)$ & $0(0)$ \\
\hline Safflower & $\mathrm{M}_{2}$ & $71.4 \%(20)$ & $25 \%(7)$ & $3.6 \%(1)$ & $0(0)$ & $0(0)$ \\
\hline \multirow{2}{*}{ Sesame } & $\mathrm{M}_{1}$ & $80 \%(20)$ & $20 \%(5)$ & $0(0)$ & $0(0)$ & $0(0)$ \\
\hline & $\mathrm{M}_{2}$ & $100 \%(10)$ & $0(0)$ & $0(0)$ & $0(0)$ & $0(0)$ \\
\hline Wheat & $\mathrm{M}_{2}$ & $91.4 \%(32)$ & $5.7 \%(2)$ & $2.9 \%(1)$ & $0(0)$ & $0(0)$ \\
\hline Total & & $78(259)$ & $17.8(59)$ & $3(10)$ & $0.9(3)$ & $0.3(1)$ \\
\hline Grand Total & & & & (332) & & \\
\hline
\end{tabular}


Table 6. Results from the model comparisons to predict the volumetric efficiency $(\eta)$ based on three criteria

\begin{tabular}{l|cccc}
\multicolumn{1}{c}{ Model no } & Model description & $\mathrm{r}$ & $\mathrm{E}_{\mathrm{RMS}}$ & $\chi^{2}$ \\
\hline I & Linear model & 0.947 & 0.0327 & 0.00108 \\
II & Volumetric efficiency transformed linear model & 0.944 & 0.0380 & 0.00145 \\
III & Volumetric efficiency transformed linear model & 0.941 & 0.0785 & 0.0062 \\
IV & Power model & 0.943 & 0.0211 & 0.00045 \\
V & Volumetric efficiency transformed power model & 0.945 & 0.0759 & 0.00579 \\
\hline
\end{tabular}

Table 7. Results from the model comparisons to predict the flow rate $(\mathrm{Q})$ based on three criteria

\begin{tabular}{l|cccc}
\hline \multicolumn{1}{c|}{ Model no } & Model ad1 & $\mathrm{r}$ & $\mathrm{E}_{\mathrm{RMS}}$ & $\chi^{2}$ \\
\hline I & Linear model & 0.998 & 3.576 & 12.858 \\
II & Volumetric efficiency transformed linear model & 0.998 & 3.598 & 13.022 \\
III & Volumetric efficiency transformed linear model & 0.998 & 3.772 & 14.298 \\
IV & Power model & 0.998 & 3.740 & 14.064 \\
V & Volumetric efficiency transformed power model & 0.999 & 3.465 & 12.081 \\
\hline
\end{tabular}

Table 8. Model prediction ranges for the volumetric efficiency $(\eta)$ and flow rate $(\mathrm{Q})$ and comparison with the measured range

\begin{tabular}{|c|c|c|}
\hline Model no & $\eta$ & $\mathrm{Q}\left(\mathrm{g} \mathrm{min}^{-1}\right)$ \\
\hline Model-I & $0.465-0.907$ & $1.831-398.168$ \\
\hline Model-II & $0.452-0.894$ & $1.833-398.825$ \\
\hline Model-III & $0.436-0.885$ & $1.833-399.196$ \\
\hline Model-IV & $0.502-0.979$ & $1.715-396.593$ \\
\hline Model V & $0.470-0.907$ & $1.696-399.410$ \\
\hline Measured & $0.469-0.890$ & $1.710-400.570$ \\
\hline
\end{tabular}

The models developed are valid within the range of variables as given below:

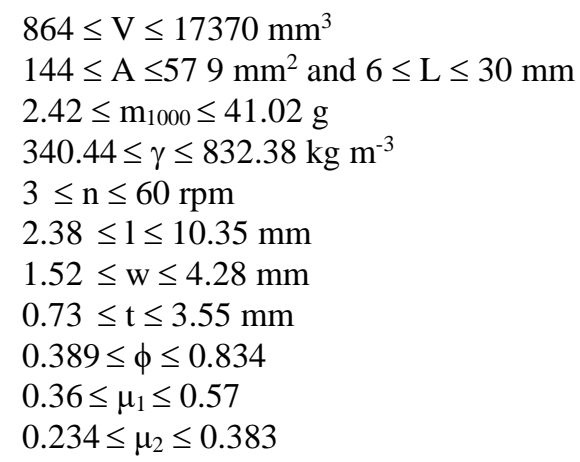

The results obtained from the comparisons of measured and predictions for the flow efficiency models from the point of correlation coefficient (r), Root mean square error $\left(E_{\mathrm{RMS}}\right)$ and Khi square values $\left(\chi^{2}\right)$ are tabulated in Table 6.

As seen from the table, the best models in terms of mass flow efficiency seem to be Model-I and IV. The model predictions have similar correlation coefficient but once the $\mathrm{E}_{\mathrm{RMS}}$ and $\chi^{2}$ values are considered; the model IV gives the better results than the other models. Actually, under the practical conditions, the flow rate prediction is of importance in terms of designing seed drills equipped with fluted rolls and the results from the comparisons are presented in Table 7.

As seen from Table 7, the flow rate predictions by Model $\mathrm{V}$ is better than other four models based on three criteria. Other than three comparison criteria, model results were evaluated in terms of range of volumetric efficiency and the results are given in Table 8 .

Based on this table, it could be stated that the range for volumetric efficiency and flow rate, Model I and Model V provides better results. On the other hand, the maximum volumetric efficiency range for Model IV is 0.979 and this creates a risk for the predictions that volumetric efficiency values may go over unity. There is no such a risk for Model II, III and V since volumetric efficiency values were transformed in a such a way that the predictions can't go over unity.

Based on above evaluations it could be stated that Model I and Model V are the candidates for volumetric efficiency and flow rate predictions. But it could be stated that Model V is the model to make better predictions than the ones made by Model I. The measured volumetric efficiency and predicted efficiencies by Model $\mathrm{V}$ are depicted for all data obtained in this study (Figure 6). As seen from the figure the data accumulates around the diagonal line that represents perfect fit and the correlation (r) was found to be 0.945 .

In terms of flow rate predictions made by Model V was compared against the measured flow rate data (1660 data) as seen in Figure 7. There is a good correlation between the two and the correlation coefficient is 0.999 .

The predictions from Model V were also verified with the published data. Önal ve Ertuğrul, (2011) used coated and uncoated canola, onion and carrot seeds as delivered by fluted rolls and obtained flow rate values as a function of roll length and roll speed.

The comparison of flow rates for coated canola are depicted in Figure 8. As seen from the figure, Model V over predicted the flow rate and the differences ranged between +3.33 and $+4.32 \%$ for all three-roll speed and roll lengths.

The flow rate comparisons made for uncoated canola (Figure 9) indicated that the Model $\mathrm{V}$ under predicts the flow rate but the differences are in the range of -1.48 and $-2,94 \%$.

The comparison of model $\mathrm{V}$ results with the measured flow rate for onion seeds are shown in Figure 10. The Model $\mathrm{V}$ under predicted the flow rate and the differences range between -6.32 to $-9.34 \%$ for all roll lengths and roll speed.

The comparisons for carrot seeds were also made even though the thousand seed mass of carrot seed mass (1.2 g) 
is out of the range $\left(2.42 \leq \mathrm{m}_{1000} \leq 41.02 \mathrm{~g}\right)$ for the crop seeds used to develop the models. It was found that the flow rate Model V under predicted the carrot seeds flow rate and the differences between predictions and measured data ranged between -13.93 and $-25.44 \%$. This was attributed to the fact that none of the models know how to predict for a crops seed in which the seeds properties are different than the ones used in this study.

\section{Discussion}

The flow rate measurement-based experiments in a designed test stands verified the flow rate results as obtained in other studies available in the literature. The flow rate increases as the roll length and roll speeds increases linearly. The volumetric efficiency on the other hand goes down once the roll length and roll speed increases. The shorter roll length affects the orientation of the seeds to fill the flutes and as a result, the shorter roll length significantly reduces the volumetric efficiency. Similarly, if the roll speed increases, the seeds could not find enough time to settle in the flutes and this results in reduced volumetric efficiency.

One of the interesting finding in this study is that the $\mathrm{CV}(\%)$ values are much lower than the ones obtained in the existing literature data. The detailed investigation made on the literature data indicated that the researchers mostly conducted their studies on seed drills as manufactured by the companies. It can be stated that in these drills there is usually a seed leakage or death volume that causes the volumetric efficiency go over unity and higher CV (\%) values are obtained as indicated in the literature review. Another important point is that once the data examined in these studies it is seen that the $\mathrm{CV}$ values go down following a smooth exponential line. But in this study, the CV (\%) values fluctuated within certain limits and went down generally as the roll speed increases. This could be attributed to the fact that the system used in this study was especially designed to find out the volumetric efficiency and there is no death volume or seed leakage under and or around the fluted rolls.

Güler (2004) found that the CV values ranged between 1 and $20 \%$ for alfalfa seeds at different roll speed and lengths and at different flute diameters. The lowest CV values was obtained at $6 \mathrm{~mm}$ flute diameter and this is a controversial finding once the results of $\mathrm{CV} \%$ ) values obtained in this study are examined.

Önal, (2011) reported that the volumetric efficiency values for some grains range between $0,7-0,85$ while the volumetric efficiency for alfalfa was in the neighborhood of 0.9. In this study, the volumetric efficiency was found to be ranging between 0.48 and 0.82 while the volumetric efficiency for alfalfa was in the range of 0.81-0.89.

Önal (2011) reported that for some crop seeds, the volumetric efficiency for roll speed ranging between 0-48 rpm did not affect the volumetric efficiency. But this finding was not verified by this study since the volumetric efficiency went down with an increase in roll speed. As an example, at a roll length of $30 \mathrm{~mm}$ and roll speed ranging between 9-40 rpm for wheat seeds, the volumetric efficiency reduced from 0.82 to 0.76 .

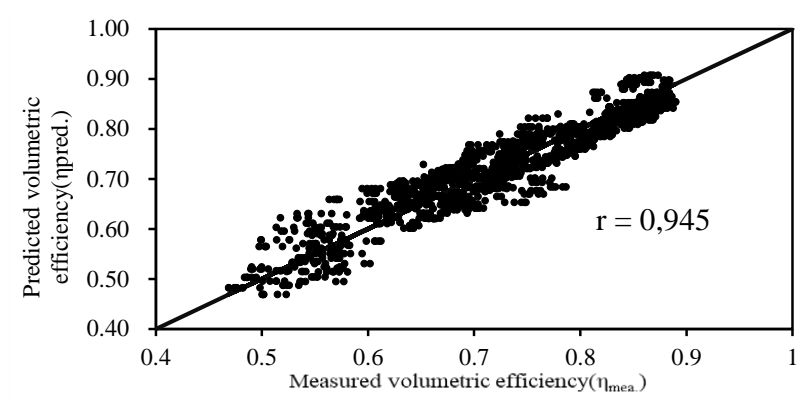

Figure 6. Comparison of measured $\left(\eta_{\text {mea. }}\right)$ and predicted $\left(\eta_{\text {pred. }}\right)$ volumetric efficiency using Model V

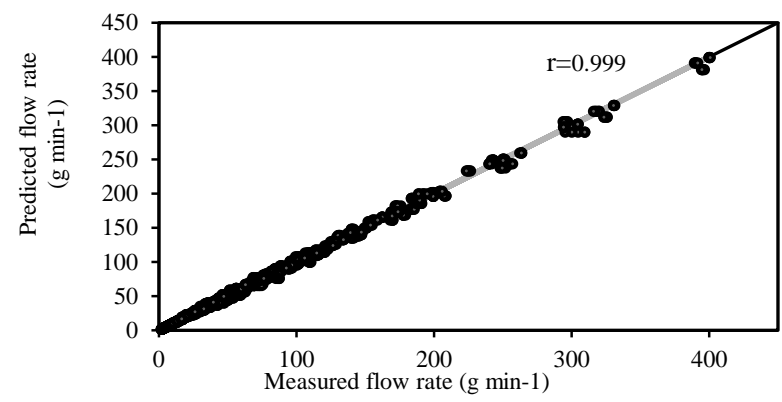

Figure 7. Comparison of measured and predicted flow rate (Q) using Model V

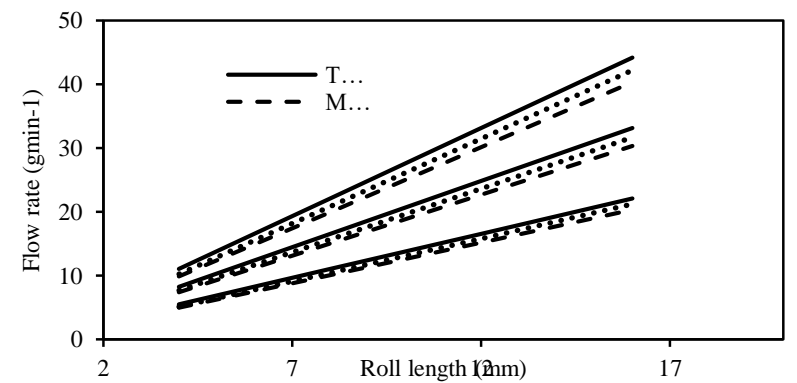

Figure 8. Predictions from Model V for the flow rate of coated canola seeds at different roll lengths and speeds

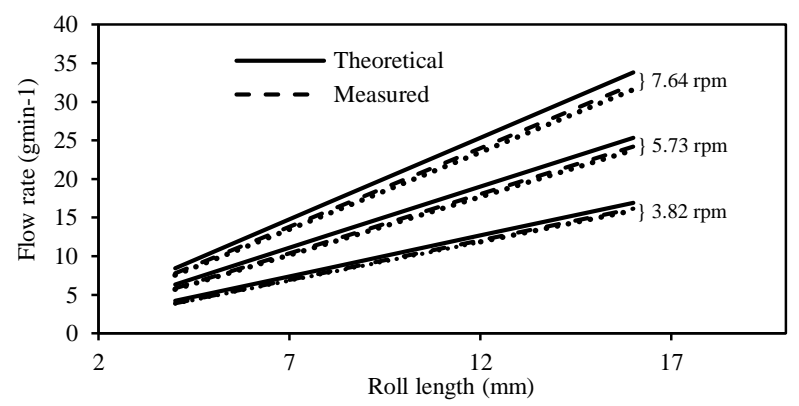

Figure 9. Predictions from Model V for the flow rate of uncoated canola seeds at different roll lengths and speeds

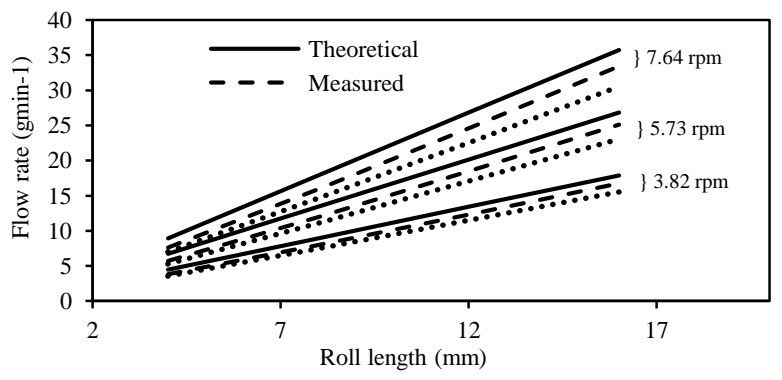

Figure 10. Predictions from Model V for the flow rate of onion seeds at different roll lengths and speeds 


\section{Conclusions}

The followings were concluded from the study conducted:

- The flow rate of the seeds increases as the roll speed (rpm) and roll length increase but this increase is not completely linear.

- The volumetric efficiency of grains ranged between 0.48 and 0.82 .

- The volumetric efficiency of the seeds with low thousand seed mass was lower for the small diameter rolls than greater diameter roll. As an example, the volumetric efficiency fo flax seeds was 0.63 and 0.84 for the 20 and $50 \mathrm{~mm}$ diameter roll. For coriander and sesame seeds these values were found to be 0.75 for $20 \mathrm{~mm}$ diameter roll while the volumetric efficiency was found to be 0.75 and 0.84 for $50 \mathrm{~mm}$ diameter roll. For alfalfa seeds, the volumetric efficiency values did not change.

- The data obtained from the experiments indicated that the flow uniformity $(\mathrm{CV}, \%)$ values did not change as the speed of the roll increased. The CV (\%) values were generally lower than $2 \%$.

- The models developed in this study showed that the roll speed, friction coefficient, an increase in seed length reduced the volumetric efficiency while the total volume (total cross section and length of roll), bulk density, an increase in thickness and width resulted in an increase in volumetric efficiency.

- Manufacturing the drillers equipped with fluted rolls in such a way that free flow can be eliminated since free flow causes an increase in flow uniformity.

\section{References}

Ertugrul Ö. 2010. Mathematical and statistical analysis of different seeding methods and the development of metering units for canola (Brassicca napus 1. sp. oleifera) seeds. (PhD Diss.in Turkish), Ege University, Department of Agricultural Machinery, İzmir-Turkey.

Güler IE. 2005. Effects of flute diameter, fluted roll length and speed on alfalfa seed flow. Applied Engineering in Agriculture, 21(1):5-7.

Minitab. 2019. Statistical Software, User Manual. Getting started with Minitab 19 for Windows, www. minitab.com, (V19; Free Trial Version).

Mohsenin NN. 1986. Physical properties of plant and animal materials. Gordon and Breach Science Publishers, New York.

Onal I. 2006. Seeding, maintenance and fertilizing machines. [in Turkish] (3rd ed, Vol.490, pp.623), Izmir, Turkey: Publications of Ege University, İzmir-Turkey.

Onal I, Ertugrul Ö. 2011a. Seed flow and in-row seed distribution uniformity of the top delivery type fluted roller for onion, carrot and canola seeds. Journal of Agricultural.Sciences, 17:10-23.

Onal I, Ertugrul Ö. 2011b. Seed flow and in-row seed distribution uniformity of the top delivery type mini fluted roller for onion, carrot and canola seeds. Journal of Agricultural Machinery Science, 7(4): 437-448.

Ryu I, Kim KU. 1998. Design of roller type metering device for precision planting. Transactions of the ASAE, 41(4): 923930.

Turgut N, Özsert İ, Kara M. and Güler İE. 1996. Performance of fluted feed rolls in seed drills. $6^{\text {th }}$ International Congress on Agricultural Mechanization and Energy. Ankara, Turkey, Congress proceedings, pp.: 344-352.

Tülek C. 2011. Seeding performance of different types of seeding units for legume and grass fodder crop seeds. (MS Thesis in Turkish) Ege University, Department of Agricultural Machinery. Izmir-Turkey.

Yildırım Y, Kara M, Turgut N. 2004. Effect of flute shape on seed flow evenness in rollers installed on cereal seeders. (in Turkish). $22^{\text {th }}$ National Congress on Agricultural Machinery, Aydin, Turkey, Congress proceedings, pp.: 148-155.

Yildırım Y, Turgut N. 2007. Investigation of flow properties of alfalfa and sesame from feed roller with different groove shape. Journal of Agricultural Machinery Science 3(1):51-58.

Zender FN, Önal İ. 1987. A research on the mechanization possibilities of the sowing of food legumes (in Turkish). Ege Üniv. Ziraat Fak. Dergisi., 24(2): 297-307. 